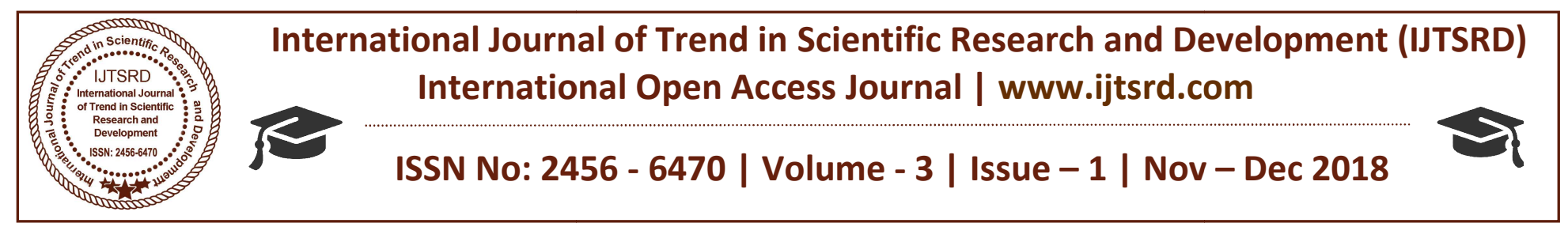

\title{
IoT Based Border Alert and Secured System for Fisherman
}

\author{
Uthayakumar Jothilingam ${ }^{1}$, Liston Deva Glindis ${ }^{2}$ \\ ${ }^{1}$ Master of Engineering, ${ }^{2}$ Assistant Professor \\ Computer Science Engineering, Dhanalakshmi Srinivasan College of Engineering, \\ Coimbatore, Tamil Nadu, India
}

\section{ABSTRACT}

An embedded system which protects the fishermen by notifying the country border to them by using Global Positioning System (GPS) and Global system for mobile communication (GSM). Using GPS, we can find the current latitude and longitude values and is sent to the microcontroller unit. Then the controller unit finds the current location by comparing the present latitude and longitudinal values with the predefined value. Then from the result of the comparison, this system aware the fishermen that they are about to reach the nautical border. Looking at this operation from an IoT (Internet of Things) lens, and taking account of the latest technology, it seems necessary and desirable to integrate the data sources to make sure that the perspective that decision makers need is based on a complete picture of the situation not just whether the traveler or a vehicle is on the watch list. This paper looks at some of the issues and opportunities that appear to be worth considering. It is necessarily a cursory look presented in the hope that it will be of use as the thought process for such a project starts. These are strictly personal views of the authors who have no connection with any law-enforcement agency If the boat enters the zone nearer to the restricted zone the alarm will turn on and the speed of the boat engine automatically gets controlled by the concern authority and once it touches the restricted zone and its pulled back to the non restricted area.

KEY WORDS: Global Positioning System (GPS), Global system for mobile communication (GSM), nautical border

\section{INTRODUCTION}

In this modern, fast moving and insecure world, it has become a basic necessity to be aware of one's safety. Maximum risks occur for fishermen in situations where they travel on a boat for fishing. The Tamil
Nadu fishermen even today invoke the historical rights and routinely stay into the International Maritime Boundary Line (IMBL) for fishing. From Tamil Nadu about 18,000 boats of different kinds conduct fishing along the India-Sri Lanka maritime border./ But by accidentally crossing the border without knowledge, they get shot by the Lankan navy. This leads to loss in the both humans as well as their economic incomes. We have developed a system which eliminates such problems and saves the lives of the fishermen.

In some situations they should not move after some point and they should not enter into other countries area. There is a real necessity in designing a system that can track the vehicle and send the information about the vehicle to the concerned person and alert the fishermen also. The project aims in designing a system which is capable of alerting the fisherman when their boat is crossing the country border and also displays the alert message on a Liquid Crystal Display (LCD). GPS based border alert system gives a best solution for this problem, whenever the fisherman was about to reach the boundary he can have a voice based alert and also displays the speed of the boat on LCD. So that he can go back from that point onwards.

\section{LITERATURE SURVEY}

There are several projects undertaken and various methods proposed for border alerting for small boats. Various technologies has been used to implement this keeping safety of fishermen as motto.

Following are the few papers which propose the idea of border alerting measurement and others are deliberate, using specifications that anticipate your paper as one part of the entire proceedings, and not as 
an independent document. Please do not revise any of the current designations.

Advanced Navigator and Monitoring System for Fisherman by Mrs. Supriya Lohar1 the lives of Indian fishermen is very important. Thousands of Tamil fishermen have been arrested, shot by the Sri Lankan government. Fishermen not having the knowledge of boundary, enter into the Sri Lankan boundary. Once entered into the boundary, they get caught or shot by the government. Hence to save the lives of fishermen we have designed the system which will help the fisherman not to navigate beyond the boundary by using the (Global Positioning System) GPS and (Global System for Mobile Communication) GSM. The main objective of this project is to help the fisherman not to navigate beyond the country's border. Using the GPS we can find out the current location of ship or vessel. Here we are using three boundary locations for which we are giving alert to the fisherman.

Secure and Efficient Border Crossing Indicator Application in Costal Area had been proposed by R. Sangeetha, P. V. Jothikantham and Dr. T. Senthil kumar Maritime surveillance is carried out by (and on behalf) of national authorities mainly to identify and deter (a) infringements to regulations and (b) security and safety threats. (These categories overlap and include law enforcement and compliance monitoring.) Surveillance carried out for the different domains, such as fisheries protection, environmental protection, maritime transport safety, border control, etc., in most cases falls under (a) because it is done on the basis of laws and regulations that govern these domains. Surveillance is a key element to exercise national sovereignty at sea.

Intelligent Boundary Alert System (IBAS) using GPS had been proposed by C. Sheeba thangapushpam. This system helps the fishermen in maritime navigation. The system uses a GPS which continuously receiving signals from the satellite and provide the current position of the boat based on the latitude and longitude data.ARM processor is already fetched details of the latitude and longitude of the maritime boundary. Comparison is done by the processor with stored data and current position of the boat, and it generates the alarm signal whenever the boat crosses the border. They used wireless sensor network to transmit the message to the base station, there they monitors the boat in the sea. This system provides an indication to both fisherman and to coastal guard [1].

\section{Implementation of GPS Based Security System for} Safe Navigation Of Fisherman Auto Boat is proposed by C. Vinothkumar and B. Arunkumaran ,that also uses GPS technology for navigation and vessel tracking purposes Using microcontroller, the stored border data between India and Srilanka is being compared with the current location details of the boat, and then alarm signal is being generated when the vessels crosses the border. Simply the message will be transmitted to the base station. In addition, some sensor is used to detect the natural calamities for sea way travel. The ultrasonic sensor is used for the detection of the iceberg, and MEMS is used for tsunami detection. In addition to this weather forecasting report can also be obtained with the help of temperature and humidity sensor [2].

IOT Based Nautical Monitoring System had been proposed by Kannan. K. R, Hakkem. B, Vignavi. K, Vinoth. P., Mohammed Noorul Karim. M, Rajbab The current latitude and longitude is known to both fishermen and coastal guards. The border is identified by comparing the current values with the original values and the message is sends through Wi-Fi sensor using IOT. Single antenna is used. This helps in continuous updating of the information at instantly. The low earth orbit is used to provide the connectivity without gap. This also helps in retrieving the missed messages. By using the electronic map, the navigation path can be identified. Thus it saves the lives of the fisherman and alerts the base station to provide help.

Automatic Border Alert System for Fishermen using GPS and GSM Techniques had been proposed by S. Ranjith*, Shreyas, K. Pradeep Kumar, R. Karthik. The proposed system is used to detect the border of the country through the specified longitude and latitude of the position, not only between Sri Lanka and India but all over the world. The particular layer level i.e. border can be predefined and this can be stored in microcontroller memory. The current value is compared with predefined values and if these values are same, immediately the particular operation will be done i.e, the microcontroller gives instruction to the alarm to buzzer. It also uses a message transmitter to send message to the base station which monitors the boats in the sea. 
Location Based Services using Android had been proposed by Archana Gupta, Mohammed Abdul Qadeer, Sandeep Kumar From the available GIS processing tools in Android we can realize all three types of LBS services as a mobile can be configured as a server and for that we can also use the SQ Lite database to store information as android also supports this technology. We can configure the two mobiles to provide peer-peer LBS services through SMS or MMS with the use of appropriate intents.

\section{Alert Fishers: A LIFE saving mobile Application} Mobile Application which can save time, effort and money and life by giving tips and ways to reduce the arrest of fisher beyond boundaries that is designed and implemented.

The collected information contains all the details related to countries boundary from the boundary defining department of India and Sri Lanka, and grouped them into an easy and compact application for the benefit of the each and every fisherman.

\section{WORKING PRINCIPLE}

The GPS Modem will continuously give the signal which determines the latitude and longitude and indicates the position of the fishermen to them. Then it gives the output which gets read and displayed in the LCD. The same data is sent to the mobile of the fisherman and simultaneously the same data is sent to the Sea border security. An EEPROM is used to store the data, received by GPS receiver. The hardware which interfaces with microcontroller are LCD display, GSM modem and GPS Receiver.GPS (Global Positioning System) is increasingly being used for a wide range of applications. It provides reliable positioning, navigation, and timing services to worldwide users on a continuous basis in all weather, day and night, anywhere on or near the Earth. 28 satellites inclined at $55^{\circ}$ to the equator orbit the Earth every 11 hours and 58minutes at a height of 20,180 $\mathrm{km}$ on 6 different orbital Lanes and each one of these satellites has up to four atomic clocks on board.

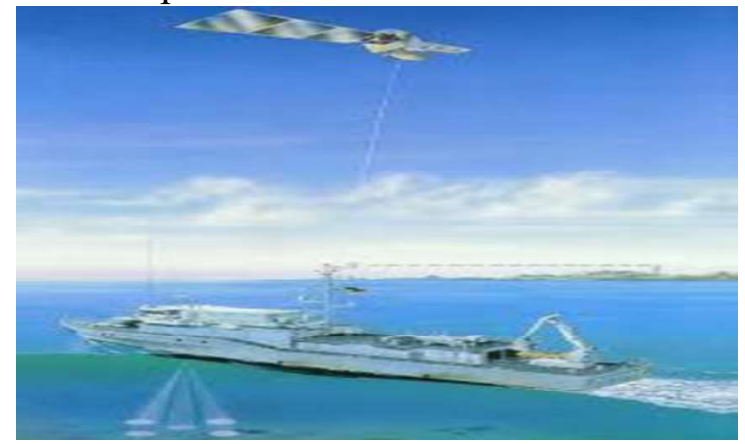

Fig. 1 GPS SIGNAL TRANSMISSION
All we require is an accurate clock. By comparing the arrival time of the satellite signal with the onboard clock time, at which the signal was emitted, the latitude and longitudinal degree of the boat's location is determined. The current design is an embedded application, which will continuously monitor a moving Boat and once the boat goes beyond the level of the defined layer the particular operation will be done. For doing so an AT89c51microcontroller is interfaced serially to a GSM MODEM AND GPS receiver

\section{EXISTING SYSTEM}

There are many disadvantages in the existing system like the lack of awareness of border which causes accident. Although, there are borders defined but it is a blue eyed vision of people of country, it is important to pay their attention.

\section{A. GPS $72 h$}

The GPS 72h equipment is used for navigation in the sea [2]. It provides the fastest and most accurate method for mariners to navigate, measure speed and determine location.

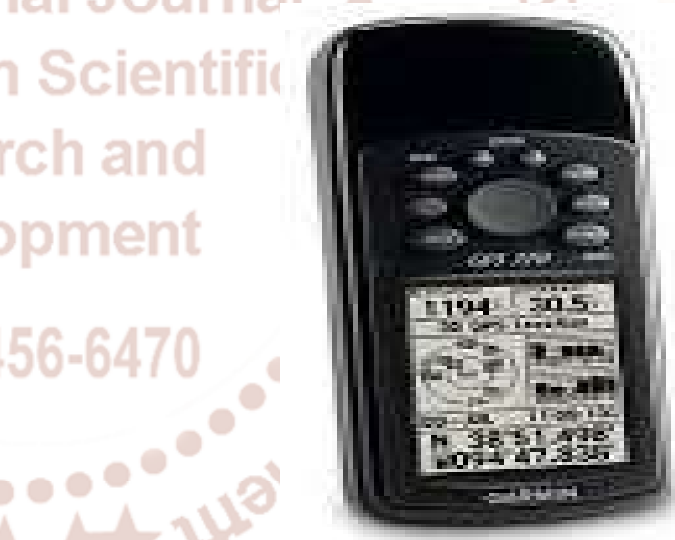

Fig. 2 GPS $72 \mathrm{~h}$

This system enables increased levels of safety and efficiency. It ensures that the ship reaches its destination safely. The accurate position information becomes even more critical as the vessel departs from or arrives in port

\section{B. Distress Alert Transmitter (DAT)}

This device was jointly developed by the Indian Coast Guard and the Indian Space Research Organization (ISRO) for fishermen [5]. INSAT based Distress Alert Transmitter (DAT) is used for transmitting conditions along with current location of the vessel to the central hub station via transponders. 


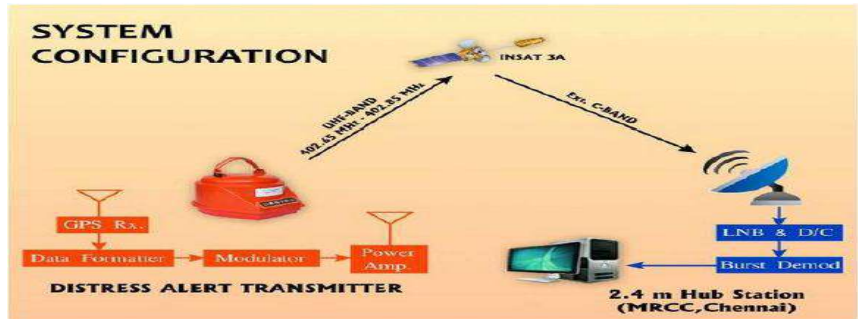

Fig. 3 DAT SYSTEM CONFIGURATION

Transponder can be easily installed in boats or other vehicles. In case of emergency, fisherman just needs to switch on the DAT unit. If Fisherman needs to transmit emergency message such as fire on vessel or medical emergency, the message can be selected by pressing the corresponding switch which is provided in the system. After pressing the appropriate switch DAT emits the signal. The message is transmitted through the satellite to the coast guard. DAT combines the message signal along with the current location of the vessel to central station. 1) Features Low Cost and therefore affordable to fishing community. - In-built GPS to give position and time information.

\section{Vessel Traffic Management System}

The System includes integrated RADAR, Automatic Identification System (AIS), Radio Direction Finders (RDF), Metrological and Hydrological Sensors, Microwave links as well as VOIP based Very High Frequency (VHF) radio system [5]All maritime traffic is recorded and movements are stored in a database.

\section{Automatic Identification System (AIS)}

In a system transponders are installed on vessels which are used to transmitting signals [5]. The data is sent from each vessel which contains current position of the vessel as well as movement information such as speed, longitude and latitude No alarming and warning for obstacles and tsunami. No security system is present which causes loss of life.

\section{DRAWBACK OF THE EXISTING SYSTEM}

The drawback of the all existing systems is that all systems give current location of the vessel and traffic monitoring, some systems transmit the emergency message to the base station. But, none of the existing system is give an alert to the fisherman about the boundary locations. Hence to save the life of fisherman we have proposed a system which gives alert to the fisherman about the boundary locations

\section{PROPOSING SYSTEM}

In the boat module microcontroller is used to control all the activities at the boat. This microcontroller is programmed in such a way as to it continuously track the boat and send GPS signals to the system at coastal guards. So once the boat crosses the safe zone the microcontroller sends a signal to stop engine of the boat and engine will be stopped. And the boat is controlled by server unit. It also helps to display various messages on LCD and voice module based on signals. GPS module with antenna is used to track the location of the boat at every instance of time. This location is sent to the base station with the help of microcontroller.LCD is used to display various alert messages for the boat at various situations and along with the LCD a voice module is also used which alert the people at the boats. The safe zone set by the control unit using keypad. The safe zone value is before the border this is useful to give the alert before crossing. The control unit receive the signal if engine is stopped or some critical situation the control unit control the boat based on the fishermen request.

\section{PROPOSED SYSTEM ARCHITECTURE}

7.1 BOAT UNIT

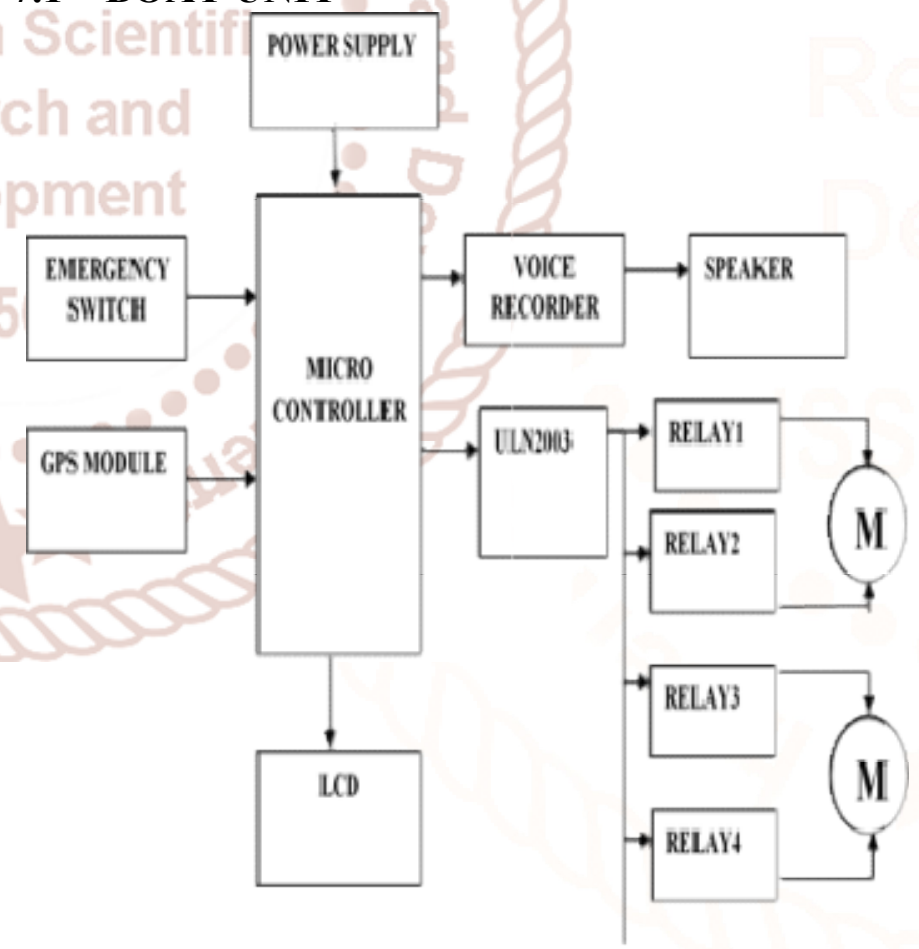

Fig. 4. PROPOSED MAIN ARCHITECTURE 
International Journal of Trend in Scientific Research and Development (IJTSRD) ISSN: 2456-6470

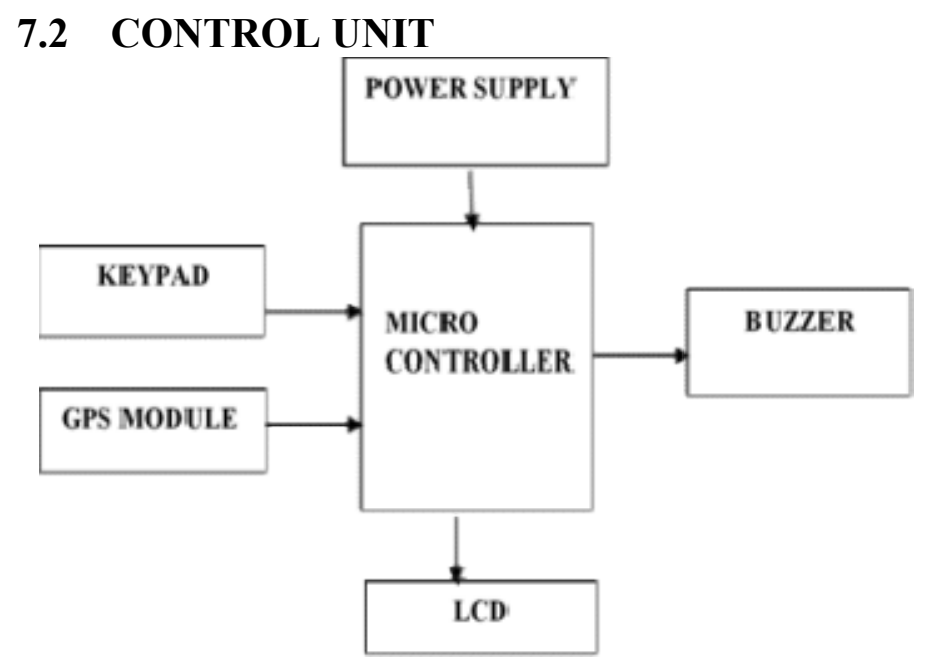

Fig. 5. PROPOSED CONTROL ARCHITECTURE

\section{PROPOSED SYSTEM FLOW DIAGRAM}

The GPS receiver receives the signal and converts it into desired data message [2]. The data is sent to the microcontroller and controller extracts the longitude and latitude information from the data. Positions get compared with the predefined locations. If the location is matched then alarm is generated and message is transmitted to the base station and also to the fisherman

\section{TECHNOLOGY USED FOR THE SYSTEM a. Global Positioning System (GPS)}

It is a space based satellite navigation system. GPS gives timing and location information in any weather conditions. GPS works in all climate conditions. GPS devices are used in military, marine and consumer product applications.

\section{b. GPS Accuracy}

The accuracy of the GPS depends on the type of receiver. Most hand-held GPS units have about 10-20 meters accuracy.

\section{c. GSM Module}

GSM Module is used for the message transmission. If the fisherman is about to cross the final boundary at that time GSM gets connected to the controller and sends an alert message to the fisherman and base station.

\section{d. Controller}

GPS is continuously connected to the controller unit. The controller receives the data from the GPS. The data contains latitude and longitude of current location of the vessel. We have already stored the boundary locations in the controller unit. When controller receives data from the GPS, controller starts comparing current location with the already stored locations. When the locations get matched then controller performs the respected operation such as it gives the instruction to the buzzer to alert the fisherman and also if fisherman neglect the alert and moves further then the controller starts comparing current location with already stored location and if the location gets matched then controller unit gives instruction to the LCD display an alert message to the fisherman.

\section{CONTROLLER MICROCONTROLLERS}

PIC

(Programmable Interface Controllers), are electronic circuits that can be programmed to carry out a vast range of tasks They are found in most electronic devices such as alarm systems, computer control systems, phones, in fact almost any electronic device PIC Microcontrollers are relatively cheap and can be bought as pre-built circuits or as kits that can be assembled by the user.

The data received contains many details along with latitude and longitude. The current positions are compared with already stored latitude and longitude of countries boundary locations. At first the latitude is compared with stored latitude which identifies if the current position is located near to the boundary. If the latitude matches then the adjacent latitudes and longitudes of the present latitude is retrieved from the microcontroller. The current position received from GPS is stored as S1 (latitude), S2 (longitude).

The latitude S1 is compared with stored latitudes. If latitude match, then adjacent latitude and longitudes $(\mathrm{X} 1, \mathrm{Y} 1$ and $\mathrm{X} 2, \mathrm{Y} 2)$ are retrieved from stored table and substituted in the equation given below: (Y$\mathrm{Y} 1) /(\mathrm{Y} 2-\mathrm{Y} 1)=(\mathrm{X}-\mathrm{X} 1) /(\mathrm{X} 2-\mathrm{X} 1)$ By simplification, we get $\mathrm{ax}+\mathrm{by}=\mathrm{c}$ Now, S1 and S2 are substituted in above equation of line. Positions Latitude Longitude Position $112^{\circ} 05^{\prime} .0 \mathrm{~N} 82^{\circ} 03^{\prime} .0$ E Position $212^{\circ} 05^{\prime} .8$ $\mathrm{N} 82^{\circ} 05^{\prime} .0$ E Position $312^{\circ} 08^{\prime} .4 \mathrm{~N} 82^{\circ} 09^{\prime} .5 \mathrm{E}$ Position $412^{\circ} 33^{\prime} 0 \mathrm{~N} 82^{\circ} 46^{\prime} .0 \mathrm{E}$

\section{LAYER CONSTRUCTION CONSEQUENCE}

The boundary points should be stored in microcontroller and the computation is done in microcontroller with these points. Thus vessel crossing the border is being calculated. Boat Position and Navigation System contains, 


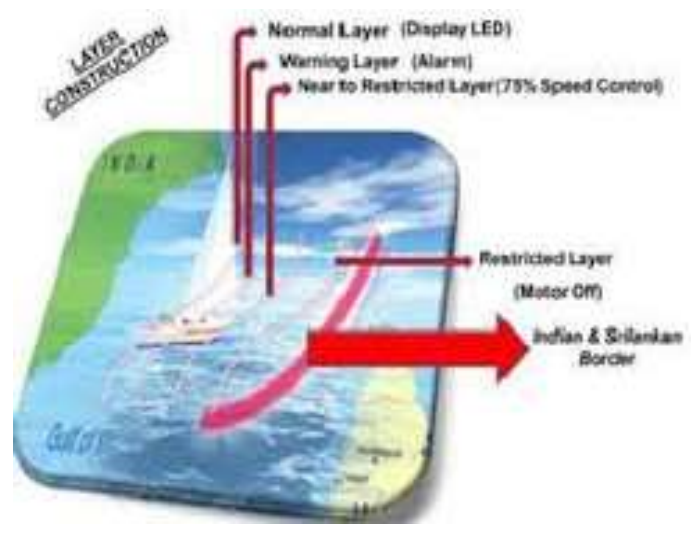

Layer1: Green LED indication

Layer2: Red LED indication

Layer3: Alarm indication \&speed control

Layer4: Engine off

\section{CALCUlating THE POSITIONS}

Because GPS receivers do not have atomic clocks, there is a great deal of uncertainty when measuring the size of the Spheres. All possible distances to the satellite are located on the circumference of the circle. If the position above the satellites is excluded, the location of the receiver is at the exact point Where the three circles intersect beneath the satellites. Because the relative size of the spheres is known, there is only one possible point where they can intersect.

\section{MARITIME BOUNDARY INDIAN AND SRI-LANKA}

BETWEEN The boundary points are marked above. These points should be stored in microcontroller. The computation is done in microcontroller with these points. Thus vessel crossing the border is being calculated. Consequence Boat Position and Navigation System contains,

Location 1: buzzer indication

$>$ Location 2: motor speed control indication.

$>$ Location 3: motor stops.

Location 4: final verification

\section{EXPERIMENTAL RESULTS}

Border alert system for fishermen is used to detect the boundary location and warn the fishermen in danger situations.

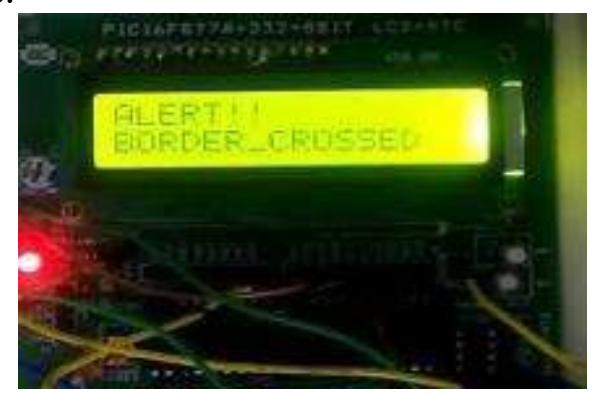

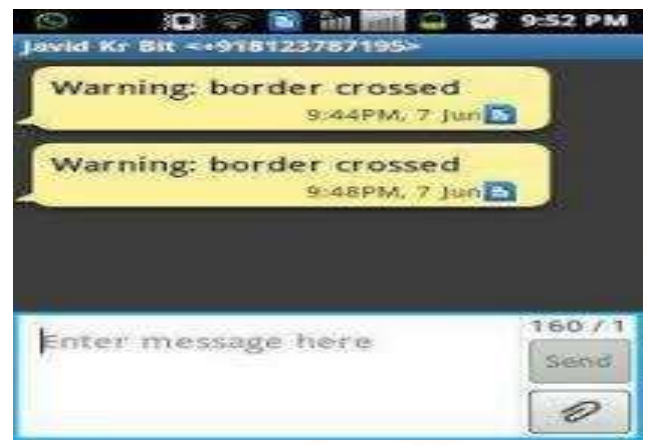

It not only finds the GPS value, but also compares with the stored value in the microcontroller, and makes a decision as to whether the fishermen is in the warning range or not.

\section{FUTURE SCOPE}

A. We can use the EEPROM to store the previous Navigating Positions up to 256 locations.

B. We can navigate up ton number of locations by increasing the memory of EEPROM.

C. We can reduce the size of the kit by using GPS + GSM on the same module of GPS navigator.

D. We can increase the accuracy up to $3 \mathrm{~m}$ by increasing the cost of the GPS receivers.

\section{BENEFITS}

$>$ The hijack of the ship by the pirates can be eradicated.

The lost ship wrecks due to natural calamities can be identified

By keeping the kits in the entire boats and by knowing the locations of all the boats we can use our kit to assist the traffic.

$>$ In case of any accident on the sea. it can be detected by the system and the accident location of the boat is sent to the rescue team.

\section{CONCLUSION}

D Risk of fishermen in border line due to unknowingly crossed the border could be reduced by this system.

Thus saving their lives and providing good relationship with the neighboring countries. Also, the piracy of ship can be easily brought under control.

$>$ It is not easy to find the border range as in land for anyone in marine region. When they crossed the border limit they have to pay penalty or got arrested by neighbor country navy guards.

$>$ This project helps the fishermen to guide by navigation and alerting them when reached the border limit. 
$>$ By using emergency switch fishermen can be navigated back if they have lost their way in the sea or can be sent help if they are in danger.

This concept of vessels tracking may enlarge to individual's vehicle security, with the GSM transmitter.

\section{REFERENCES}

1. Hanjiang luo ,student member IEEE kaishun wu member IEEE zhongwen guo member IEEE Lin $\mathrm{Gu}$ member IEEE and Lionel $\mathrm{M}$ Ni fellow IEEE "Ship detection with wireless sensor network" IEEE transactions on parallel and distributed system vol.23 no.7 july 2012

2. D. Arunvijay, E. Yuvraj "Design of border alert system for fishermen using GPS" International journal of students research in technology \&management vol 2 (02) march april 2014 ISSN2321-2543 pg 67-70

3. Mr. Pradip Vanparia, shri M \& N Virani, Dr. Y. R. Ghodasara "Review paper on to study and enhance coastal security system using GIS /GPS" International journal of computer application \&information technology vol.1 issue II September 2012(ISSN:2278-7720).

4. ALERT FISHERS: A LIFE SAVING Mobile Application International Journal of Scientific \& Engineering Research Volume 8, Issue 5, May201733 ISSN 2229-5518.
5. On-line GPS Track simplification Algorithm for MobilePlatforms.www.acad.bg/rismim/itc/sub/arc hiv/paper1_1_2010.pdf.

6. Peng Wang, Zhiwen Zhao, Chongbin Xu, Zushun Wu, Yi Luo," Design and Implementation of the Low-Power tracking System Based on GPSGPRS Module" proposed in 2010 5th IEEE conference on Industrial Electronics and Applications.

7. Atsushi Ito, Yoshiaki Kakuda, Tomoyuki Ohta and Shinji Inoue, "New safety support system for children on school routes using mobile ad hoc networks", IEICE Transactions on Communications, vol.E94-B, no.1, 2011, to appear.

8. Border Alert System for Boats Using Zigbee International Journal of Innovative Research in Computer and Communication Engineering (An ISO 3297: 2007 Certified Organization) Vol.2, Special Issue 1, March 2014 Proceedings of International Conference On Global Innovations In Computing Technology (ICGICT'14)

9. Safety System For Fishing Boats To Prevent From International Border Crossing International Journal Of Recent Trends in Engineering and Trends. Volume 02, Issue 04; April - 2016 [ISSN: 2455-1457]. 